\title{
Can there be true partnership between clinicians and the Home Office?
}

\author{
Invited commentary on ... The Home Office Mental Health Unit
} Nigel Eastman

Abstract Srinivas et al provide a comprehensive guide to the law, regulations and practice concerning the management of 'restricted patients', who are the responsibility of both the clinical services treating them and the Home Office. In doing so, they make the assumption, with apparent approval, that there is a 'partnership' between clinicians and the Home Office. However, partnership assumes parties working towards a common goal on an equal footing. Neither assumption is correct here. Although forensic mental health services direct themselves explicitly towards enhancing public safety, they do so in conjunction with treatment aimed at the relief of dysphoria in the patient. The interest of the Home Office in the patient's mental health is solely in terms of its impact on the risk of harm to others. There is therefore no 'partnership'. Rather, there is constructive tension between agencies working towards differently valued and balanced objectives. Certainly the relationship is not one of equal power.

The relationship between the Home Office and clinicians caring for mentally disordered offenders offers a highly focused model of both the need for cooperation in managing such individuals and the profound ethical problems inherent in doing so. Although some argue that violence is a public health issue, and that this automatically validates cooperation between health and justice agencies, there is a risk that cooperation between what are ethically highly differentiated agencies will drift into mutual contamination of what should be their different social functions, properly pursued by each through its own distinct set of legal and ethical rules. Ultimately how the relationship between the Home Office and clinicians operates 'on the ground', in respect of individual clinicians and services, will reflect the ethical positions taken by those clinicians and services on how the balance between care for the patient and protection of the public should be struck. And striking that balance is at the heart of a major ethical debate within forensic psychiatry concerning the proper boundaries and social roles of the discipline (Eastman, 1999; Coid \& Maden, 2003).

The article by Srinivas et al (2006, this issue) is extremely helpful in describing the 'nuts and bolts' of the legal rules governing the role of the Home Office, and its relationship with clinicians and services, in a comprehensive way. However, what is missing is any real sense of the potential for major ethical conflict that, for the clinician, can lie within the arrangements. This may reflect the brief the authors were given. But, as written, there is simply the implicit assumption that, because the relationship is established and governed by statute, it is thereby validated in whatever manner the Home Office might require. Although passing mention is made of possible conflicts between the parties, in essence what is described is a (comfortable) partnership between Home Office officials and clinicians who are all working towards the same end; that is, a safer society that will thereby also enhance the welfare of mentally disordered offenders by helping them to avoid reoffending. In this way the article reinforces an attitude of mind which is increasingly influencing forensic psychiatry, that is, that it is primarily in the business of risk management and public protection (Coid \& Maden, 2003). Indeed, acceptance without demur by some clinicians, for example, of Home Office direction of 'end of sentence' prisoners to NHS 'dangerous people with severe personality disorder' (DSPD) services for what can be essentially preventive detention with little patient benefit per se, emphasises the 'ethical drift' which is occurring at least in some pockets of forensic psychiatry. And this can be contrasted with the position adopted by the Royal College of Psychiatrists in relation to DSPD services (Shooter \& Cox, 1999) and with the opinion of most psychiatrists concerning preventive detention (Roberts et al, 2002).

Clearly forensic psychiatric services do, and should, aid public protection. However, the core of what they properly do is treat patients, with the aim of coincidental benefit to the public. And it is the 
key issue of 'treatability', or (better put) 'therapeutic benefit', which has therefore been at the centre of the dispute between the government and the Mental Health Alliance concerning reform of mental health legislation, since it is the requirement of pursuing at least some therapeutic benefit to the patient which protects the social role of mental health services from being that of 'gaoler'. In fact the proposal for new legislation is referred to within the article, although it was written before the government's apparent climb down from its attempt to achieve a new Mental Health Act in favour of a Bill amending the 1983 Act (Department of Health, 2006; Eastman, 2006). Yet there is no reference to the profound dispute that there has been between the government and virtually every body that has an interest in mental healthcare concerning reform, including no mention of the government intention to abolish the treatability test. And this exemplifies the tone of the article as a whole which, as I have suggested, fails to highlight the inherent tension between agencies concerned primarily with treating patients and a Home Office concerned almost exclusively with public protection. It is not that it is necessarily wrong to describe some sort of collaboration between healthcare and the Home Office, it is that such description should highlight the inherent conflict in the collaboration, a conflict which, even under current legislation, ultimately favours the Home Office. Indeed, the latter is highlighted by the authors' description of the rule that allows the Home Office to recall a patient to hospital for treatment even against the wishes of the 'responsible medical officer' (RMO) who will oversee such treatment. That is not to say that the power is wrongly given, but merely to demonstrate the inherent conflict there can sometimes be between clinicians and the Home Office.

At the heart of the manner of fashioning the relationship between the Home Office and the RMO, and team, is the extent to which the clinician sees him/herself as essentially acting as a doctor, with all of the accompanying ethical and legal rules of being so, or alternatively to what extent s/he pursues a 'collaborative venture' with the Home Office sometimes even in spite of conventional medical ethics. The article itself leans very strongly towards the latter. However, my criticism is not so much that it does so as that it fails to highlight the ethical choice that such a position reflects. Ethical analysis is crucially about being fully aware of the ethical implications of making decisions in one way, as opposed to some other way. Yet this article reveals little awareness of the inherent tension present within the relationship between the Home Office and clinician, even though it is within the legal rules which they describe so comprehensively that this ethical tension is, or should, be played out.
Indeed, the article even explicitly refers to a 'partnership' between clinicians and the Home Office in the management of restricted patients, doing so with apparent approval of such an approach. However, this is grossly to misuse the term. A partnership involves parties working towards a common goal, through an agreed process and on an equal footing. None of these aspects characterises the relationship between the clinician and Home Office in managing a restricted patient. Although forensic mental health services direct themselves explicitly towards enhancing public safety, they do so in conjunction with treatment aimed at the relief of dysphoria in the patient. The interest of the Home Office in the patient's mental health is solely in terms of its impact on the risk of harm to others, or at least overridingly so. There is, therefore, no 'partnership'. Rather, there is a natural, and sometimes constructive, tension between agencies working towards differently valued and balanced objectives. And certainly the relationship is not one of equal power. Only the Mental Health Review Tribunal can override the Home Secretary's authority, and then only through the 'ultimate decision' to discharge the patient. Neither doctor nor Tribunal can determine even a move between levels of security without Home Office agreement. If this is a partnership, it is a Victorian and not a modern marriage, with the Home Office as the disciplinarian father and the clinician as the caring mother.

Reference in the article to multi-agency public protection arrangements (MAPPA) could have offered a useful model for discussing and teasing out the ethical tensions inherent in treating mentally disordered offenders. MAPPA directly reflect the new era of multi-agency working, placing doctors alongside police officers, for example, in discussing their patients and in managing the risks they pose. Again, that is not necessarily wrong in individual cases. But it is crucial that the doctor is constantly aware of the ethical problems inherent in doing so and of the ethical and legal rules which govern his own professional functioning as a doctor. Hence, breach of medical confidence 'in the public interest' must be based on the legal rule in W. v. Egdell [1990] that, without breach, there would be a significant risk of serious harm to the public. This 'public protection' basis for breach should be seen as entirely distinct from breach on a 'need to know' basis, designed legally to allow breach to a third party where the purpose of that breach is the therapeutic benefit of the patient. It is spurious to use 'need to know' as a basis for breach where the 'need' is of agencies which are solely concerned with public protection and the detection of crime. Yet multiagency working can rapidly result in blurring of the distinction, with all participants pursuing what 
seems the entirely reasonable joint venture of public protection.

Where the article does, at least impliedly, address ethical matters there is ethical confusion, demonstrated by some loose thinking concerning what is clinical and what is public protection. The assumption is repeated that the RMO is responsible for things clinical while the Home Office concentrates on public protection, suggesting some sort of separation of responsibilities. Yet frequently Srinivas et al go on to talk as if the two are indistinguishable. And this is realistic, since clinical treatment and risk management almost invariably run one into the other. Hence, by analogy, there cannot simply be nurses in a secure ward treating the patient and 'guards' responsible for security, since part of achieving security comes from adequate treatment, and risk assessment involves collecting clinical data. Yet the fact that it is still the norm for the Home Office to refuse to conditionally discharge a patient, on the advice of the RMO, thus forcing the patient to appeal to a Mental Health Review Tribunal, is accepted by the authors without comment, other than to say that the Home Office is becoming less conservative in this regard. What sort of partnership is it where one party usually insists upon 'going to law' in order to decide key issues? Some partnership! And some mutual trust, within which the Home Office not uncommonly fails to acknowledge that good clinical management and good risk management are often intimately intertwined, and insists upon RMOs continuing to treat many patients in hospital beyond when they consider it proper to do so.
This is a rather harsh critique of what is an informative article. But what concerns me most is the tone of the article and the lack of attention to ethical or legal detail (legal in the context of fashioning the relationship between RMO and the Home Office). What is required is a 'sister article' which does address some of the ethical problems for clinicians inherent it operating the legal rules which are otherwise so well described in the authors' article.

\section{References}

Coid, J. \& Maden, T. (2003) Should psychiatrists protect the public? BMJ, 326, 406-407.

Department of Health (2006) Next Steps for the Mental Health Bill. Press Announcement, 23 March, no. 2006/0108. London: Department of Health.

Eastman, N. L. G. (1999) Public health psychiatry or crime prevention? BMJ, 318, 549-551.

Eastman, N. (2006) Mental health law reform in England and Wales. BMJ, 332, 737-738.

Roberts, C., Peay, J. \& Eastman, N. (2002) Mental health professionals' attitudes towards legal compulsion: report of a national survey. International Journal of Forensic Mental Health, 1, 71-82.

Shooter, M. \& Cox, J. (1999) Royal College of Psychiatrists' Response to 'Managing Dangerous People with Severe Personality Disorder: Proposals for Policy Development'. London: Royal College of Psychiatrists.

Srinivas, J., Denvir, S. \& Humphreys, M. (2006) The Home Office Mental Health Unit. Advances in Psychiatric Treatment, 12, 450-485.

W. v. Egdell [1990] 1 All ER 835.

Nigel Eastman Professor of Law and Ethics in Psychiatry, St George's, University of London, Division of Mental Health Sciences, Jenner Wing, Cranmer Terrace, London SW17 0RE. Email: neastman@sgul.ac.uk 